\title{
Diagnostic Delay in Psoriatic Arthritis: A Population-based Study
}

\author{
Paras Karmacharya ${ }^{1}\left(\mathbb{D}\right.$, Kerry Wright ${ }^{1}$, Sara J. Achenbach ${ }^{2}$, Delamo Bekele ${ }^{1}$, Cynthia S. Crowson ${ }^{3}$ (D), \\ Alexis Ogdie ${ }^{4}$, Alí Duarte-García ${ }^{5}$ (D) Floranne C. Ernste ${ }^{1}$, Megha M. Tollefson $^{6}$, and John M. Davis III ${ }^{1}$
}

\begin{abstract}
Objective. To examine demographic and clinical characteristics associated with diagnostic delay in psoriatic arthritis (PsA).

Methods. We characterized a retrospective, population-based cohort of incident adult ( $\geq 18$ yrs) patients with PsA from Olmsted County, Minnesota, from 2000-2017. All patients met the classification criteria. Diagnostic delay was defined as the time from any patient-reported PsA-related joint symptom to a physician diagnosis of PsA. Factors associated with delay in PsA diagnosis were identified through logistic regression models.

Results. Of the 164 incident PsA cases from 2000 to 2017, 162 had a physician or rheumatologist diagnosis. Mean (SD) age was 41.5 (12.6) years and $46 \%$ were female. Median time from symptom onset to physician diagnosis was 2.5 years (IQR 0.5-7.3). By 6 months, 38 (23\%) received a diagnosis of PsA, 56 (35\%) by 1 year, and $73(45 \%)$ by 2 years after symptom onset. No significant trend in diagnostic delay was observed over calendar time. Earlier age at onset of PsA symptoms, higher BMI, and enthesitis were associated with a diagnostic delay of $>2$ years, whereas sebopsoriasis was associated with a lower likelihood of delay.

Conclusion. In our study, more than half of PsA patients had a diagnostic delay of $>2$ years, and no significant improvement in time to diagnosis was noted between 2000 and 2017. Patients with younger age at PsA symptom onset, higher BMI, or enthesitis before diagnosis were more likely to have a diagnostic delay of $>2$ years, whereas patients with sebopsoriasis were less likely to have a diagnostic delay.
\end{abstract}

Key Indexing Terms: delay, diagnosis, psoriatic arthritis, spondyloarthritis

Psoriatic arthritis (PsA) is a chronic musculoskeletal (MSK) disease that can lead to progressive joint pain, joint destruction, and loss of function. The effect on quality of life and functional status is similar to that of rheumatoid arthritis (RA). ${ }^{1}$ There is also increasing evidence that early diagnosis and treatment of PsA leads to improved long-term outcomes for patients in terms of disease severity and radiographic damage., ${ }^{2,3}$ Delays in diagnosis of even 6-12 months have been shown to be associated with joint damage and poor functional outcomes. ${ }^{3,4,5}$ Similarly, treatment response may also be better in early PsA. ${ }^{4}$ Despite this, the majority of patients have significant delays in the diagnosis of PsA; up to $40 \%$ have not been previously identified in screening studies. ${ }^{6}$ Several factors contribute to delay in diagnosis of PsA. While early diagnosis is important in PsA, awareness of PsA compared to RA is poor in community practice. ${ }^{7}$ The clinical presentation of PsA is heterogeneous, and there are no definitive
This study was made possible using the resources of the Rochester Epidemiology Project, which is supported by the National Institute on Aging of the National Institutes of Health under Award Number R01AG034676, and Grant Number UL1 TR002377 from the National Center for Advancing Translational Sciences (NCATS), a component of the National Institutes of Health (NIH). The content is solely the responsibility of the authors and does not necessarily represent the official views of the NIH. PK is supported by T32 AR56950 grant from the National Institute of Arthritis and Musculoskeletal and Skin Diseases for the Musculoskeletal Research Training Program. ADG is supported by Centers for Disease Control and Prevention, the Rheumatology Research Foundation Scientist Development Award, the Robert D. and Patricia E. Kern Center for the Science of Health Care Delivery, the Women's Health Career Enhancement Award, and the Eaton Family Career Development Award.

${ }^{I}$ P. Karmacharya, MBBS, K. Wright, MBBS, D. Bekele, MBBS, F.C. Ernste, MD, J.M. Davis III, MD, MS, Division of Rheumatology, Mayo Clinic; ${ }^{2}$.J. Achenbach, MS, Department of Health Sciences Research, Mayo Clinic; ${ }^{3}$ C.S. Crowson, PhD, Division of Rheumatology, and Department of Health Sciences Research, Mayo Clinic, Rochester, Minnesota; ${ }^{4}$ A. Ogdie, MD, MSCE, Departments of Medicine/Rheumatology and Biostatistics, Epidemiology and Informatics, Perelman School of Medicine, University of Pennsylvania, Philadelphia, Pennsylvania; ${ }^{5}$ A. Duarte-García, MD, MSc, Division of Rheumatology, and Robert D. and Patricia E. Kern Center for the Science of Health Care Delivery, Mayo Clinic; ${ }^{6}$ M.M. Tollefson, MD, Robert D. and Patricia E. Kern Center for the Science of Health Care Delivery, Mayo Clinic, Rochester, Minnesota, USA.

$A O$ has served as a consultant for AbbVie, Amgen, BMS, Celgene, Corrona, Janssen, Lilly, Novartis, and Pfizer (<\$10,000 each), and has received grants from Novartis and Pfizer to Penn and from Amgen to Forward (grants > $\$ 10,000)$. JMD has received consulting fees and/or honoraria from AbbVie and Sanofi-Genzyme (<\$10,000 each) and research support from Pfizer. No other disclosures are relevant to this article.

Address correspondence to Dr. P. Karmacharya, Division of Rheumatology, Mayo Clinic College of Medicine, 200 First Street S.W., Rochester, MN 55905, USA.Email:paraskarmacharya@gmail.com.

Accepted for publication February 2, 2021. 
gold-standard diagnostic tests. Similarly, patients with psoriasis ( $\mathrm{PsO}$ ) may not report joint symptoms or be aware of joint inflammation. Moreover, patients with $\mathrm{PsO}$ can have joint pain due to other common etiologies, such as osteoarthritis (OA), gout, and fibromyalgia. ${ }^{6,8}$ Another issue is that approximately $10-15 \%$ of patients develop arthritis prior to $\mathrm{PsO}$, posing additional difficulties with diagnosis.

Only a few studies have examined delay in diagnosis of PsA, most of which relied on patient surveys or administrative data for ascertainment of the date of PsA diagnosis, which may be misleading. A study from Europe showed improvement in time to diagnosis for PsA. ${ }^{10}$ However, the trends in diagnostic delay of PsA in the USA and factors associated with delay in diagnosis have not been well studied. Lack of longitudinal, population-based PsA cohorts in the United States has made this type of study difficult. The aims of our study were to (1) examine the diagnostic delay in PsA in residents of Olmsted County from 2000 to 2017, and (2) identify demographic and clinical characteristics associated with diagnostic delay in PsA.

\section{METHODS}

Data source. A retrospective inception cohort of Olmsted County, Minnesota residents with PsA between 2000 and 2017 was assembled. Olmsted County, in which resides the city of Rochester, has a population that is well suited for investigation of the epidemiology of PsA, as comprehensive medical records for all residents seeking medical care for over 5 decades are available. A record linkage system allows ready access to the medical records from all healthcare providers for the local population, including the Mayo Clinic, the Olmsted Medical Center and affiliated hospitals, local nursing homes, and the few private practitioners. ${ }^{11,12}$ The population of Olmsted County in 2010 was 144,248, with $74.7 \%$ being adults $\geq 18$ years old. Patients who denied authorization to use their medical records for research were excluded. The study was approved by the Mayo Clinic (18-010851) and Olmsted Medical Center (051-OMC-18) institutional review boards.

Patient population and case ascertainment. PsA cases were defined as patients fulfilling ClASsification of Psoriatic ARthritis (CASPAR) criteria for PsA (sensitivity of $91.4 \%$ and specificity of $98.7 \%$ ). ${ }^{13}$ International Classification of Diseases, 9th and 10th revisions, diagnostic codes for arthralgias, arthritis, monoarthritis, oligoarthritis, polyarthritis, spondylitis, ankylosing spondylitis, arthropathy, psoriatic arthropathy, spondyloarthropathy, and seronegative spondyloarthropathy were used to screen for patients with PsA. Medical record chart review of all potential cases was performed to ascertain fulfillment of the CASPAR criteria. Questionable cases were resolved by mutual agreement between study investigators. Patients $\geq 18$ years old fulfilling CASPAR criteria between January 1, 2000, and December 31, 2017, were included in the PsA incidence cohort.

Outcomes. The primary outcome of interest was delay in diagnosis of PsA $>2$ years (i.e., the time from symptom onset to establishment of PsA diagnosis). Secondary outcomes were delays in PsA diagnosis of $>6$ months or $>1$ year. Symptom onset was defined as the first PsA-related MSK symptom (not explained by other diagnoses) documented by a clinician in the medical records. PsA-related MSK symptoms were defined as joint- or enthesis-related symptoms documented in the medical records that did not have a clear explanation other than PsA, such as trauma/injury, gout, fibromyalgia, or degenerative joint disease. ${ }^{14}$ MSK symptoms included were arthralgia, morning joint stiffness, pain or stiffness at entheseal sites, and inflammatory back pain. The PsA diagnosis date was the date the patient was diagnosed by a rheumatologist. For patients meeting CASPAR criteria but never seen by a rheumatologist, confirmatory diagnosis of PsA by any physician was included. Time to diagnosis was defined as the time from onset of symptoms to the establishment of PsA diagnosis. Radiographic damage was defined based on variables of joint erosion, destruction, and proliferation from hand/wrist and feet radiographs included in the Sharp/van der Heijde score modified for PsA (Table 1).15

Covariates of interest. Complete medical records from all healthcare providers were identified and reviewed for each patient by a rheumatologist (PK), using a standardized, pretested data abstraction form in the Research Electronic Data Capture (REDCap) system for consistency. Information regarding demographics, clinical characteristics, laboratory data, and radiographic features were collected. $\mathrm{PsO}$ was confirmed by documentation of diagnosis in the medical record by either a dermatologist, rheumatologist, or positive skin biopsy. Severity of $\mathrm{PsO}$ was defined based on body surface area involvement, distribution of involved sites, and requirement for phototherapy or systemic therapy as documented in the medical records.

Statistical analysis. Descriptive statistics (medians, percentages, etc.) were used to summarize the data. Chi-square, Fisher exact, or Wilcoxon rank-sum tests were used to compare characteristics between groups. Logistic regression models adjusted for age and sex were performed to identify factors associated with delay in PsA diagnosis. Trends in time from symptom onset to diagnosis of PsA were examined using linear regression models, adjusted for age and sex with and without log transformation of the delay to address skewness. Model diagnostics were examined. Analyses were performed using SAS version 9.4 (SAS Institute) and R 3.6.2 (R Foundation for Statistical Computing).

\section{RESULTS}

A total of 164 patients aged $\geq 18$ years old were identified who fulfilled CASPAR criteria between January 1, 2000, and December 31, 2017 (Figure 1). Two patients who did not have a physician diagnosis of PsA were excluded. The remaining 162 patients with incident PsA were included in this study. A rheumatologist made the diagnosis of PsA for 160 patients, and the remaining 2 patients received a confirmatory diagnosis of PsA by internal medicine physicians. Both of them clearly met CASPAR criteria and had characteristic distal interphalangeal erosions on radiographs. The mean (SD) age at PsA symptom onset in the cohort was 41.5 (12.6) years, and 46\% were female.

Median time to diagnosis from first PsA-related joint symptom was 2.5 years (IQR 0.5-7.3). By 6 months after symptom onset, 38 patients (23\%) received an established diagnosis of PsA, 56 (35\%) by 1 year, and 73 (45\%) by 2 years. No significant trend in time to diagnosis was observed during the study period of 2000-2017 ( $P=0.84$; Figure 2). There were no significant differences between those with and without diagnostic delay in terms of sex, education level, smoking status, alcohol intake, $\mathrm{PsO}$ severity or location, nail involvement, family history of $\mathrm{PsO}$ or $\mathrm{PsA}$, history of extraarticular manifestations (i.e., uveitis, inflammatory bowel disease), or high inflammatory markers at the time of diagnosis (Table 1).

PsA patients of younger age at PsA symptom onset (OR per 10 -year decrease $=1.34,95 \%$ CI 1.04-1.74), higher BMI (OR per $10 \mathrm{~kg} / \mathrm{m}^{2}$ increase $=1.89,95 \%$ CI $\left.1.15-3.10\right)$, and enthesitis at or before diagnosis (OR 2.20, 95\% CI 1.08-4.46) were associated with a diagnostic delay of $>2$ years (Table 2). Sebopsoriasis at diagnosis was associated with a lower likelihood of delay of $>2$ years (OR 0.19, 95\% CI 0.04-0.97). Radiographic damage at PsA diagnosis showed a possible association with a delay in diagnosis of $>2$ years (OR 1.63, 95\% CI 0.78-3.41), but this 
Table 1. Baseline characteristics of patients with PsA with delay in diagnosis of 2 or fewer years compared to more than 2 years.

\begin{tabular}{|c|c|c|c|c|}
\hline & $\leq 2$ yrs, $\mathrm{n}=73$ & $>2$ yrs, $\mathrm{n}=89$ & Total, $\mathrm{n}=162$ & $P$ \\
\hline $\begin{array}{l}\text { Time from PsA symptom onset to physician/ } \\
\text { rheumatologist diagnosis of PsA, yrs, median (IQR) }\end{array}$ & $0.5(0.2-1.0)$ & $6.5(3.5-10.1)$ & $2.5(0.5-7.3)$ & - \\
\hline Age at PsA symptom onset, yrs, mean (SD) & $44.0(12.4)$ & $39.5(12.4)$ & $41.5(12.6)$ & 0.04 \\
\hline Sex, female, $\mathrm{n}(\%)$ & $36(49)$ & $39(44)$ & $75(46)$ & 0.48 \\
\hline Education level, $\mathrm{n}(\%)$ & & & & 0.79 \\
\hline$\geq 4$-yr college degree & $29(40)$ & $37(42)$ & $66(41)$ & \\
\hline Missing, $\mathrm{n}$ & 1 & 0 & 1 & \\
\hline Race, n (\%) & & & & 0.02 \\
\hline Black & $2(3)$ & $2(2)$ & $4(2)$ & \\
\hline Asian & $0(0)$ & $8(9)$ & $8(5)$ & \\
\hline Hispanic & $6(8)$ & $3(3)$ & $9(6)$ & \\
\hline Missing, $\mathrm{n}$ & 4 & 5 & 9 & \\
\hline Smoking at PsA diagnosis, $\mathrm{n}(\%)$ & & & & 0.53 \\
\hline Current smoker & $12(16)$ & $15(17)$ & $27(17)$ & \\
\hline Past smoker & $23(32)$ & $35(39)$ & $58(36)$ & \\
\hline Never smoker & $38(52)$ & $39(44)$ & $77(48)$ & \\
\hline Alcohol intake at PsA diagnosis, $\mathrm{n}(\%)$ & $56(77)$ & $65(73)$ & $121(75)$ & 0.59 \\
\hline $\mathrm{PsO}$ (current or personal history), $\mathrm{n}(\%)$ & & & & 0.15 \\
\hline $\mathrm{No} \mathrm{PsO}$ & $2(3)$ & $5(6)$ & $7(4)$ & \\
\hline Current $\mathrm{PsO}$ & $70(96)$ & $78(88)$ & $148(91)$ & \\
\hline Personal history of $\mathrm{PsO}$ & $1(1)$ & $6(7)$ & $7(4)$ & \\
\hline Family history of $\mathrm{PsO}, \mathrm{n}(\%)$ & $24(40)$ & $35(49)$ & $59(45)$ & 0.32 \\
\hline Missing, $\mathrm{n}$ & 13 & 17 & 30 & \\
\hline Type of $\mathrm{PsO}$ at first diagnosis, $\mathrm{n}(\%)$ & & & & 0.03 \\
\hline Chronic plaque $\mathrm{PsO}$ & $56(80)$ & $74(88)$ & $130(84)$ & \\
\hline Guttate $\mathrm{PsO}$ & $3(4)$ & $1(1)$ & $4(3)$ & \\
\hline GPP & $1(1)$ & $0(0)$ & $1(1)$ & \\
\hline PPP & $2(3)$ & $4(5)$ & $6(4)$ & \\
\hline Sebopsoriasis & $5(7)$ & $0(0)$ & $5(3)$ & \\
\hline Chronic plaque $\mathrm{PsO}+$ guttate $\mathrm{PsO}$ & $0(0)$ & $3(4)$ & $3(2)$ & \\
\hline Chronic plaque + PPP & $1(1)$ & $0(0)$ & $1(1)$ & \\
\hline Chronic plaque + sebo $\mathrm{PsO}$ & $2(3)$ & $2(2)$ & $4(3)$ & \\
\hline No documentation/missing & 3 & 5 & 8 & \\
\hline Site of psoriatic lesions at first $\mathrm{PsO}$ diagnosis, $\mathrm{n}(\%)$ & & & & 0.65 \\
\hline Palms and/or soles & $1(5)$ & $3(15)$ & $4(10)$ & \\
\hline Elbows and/or knees & $3(14)$ & $4(20)$ & $7(17)$ & \\
\hline Limbs: arms and/or legs & $5(23)$ & $5(25)$ & $10(24)$ & \\
\hline Trunk & $0(0)$ & $1(5)$ & $1(2)$ & \\
\hline Face & $1(5)$ & $0(0)$ & $1(2)$ & \\
\hline Scalp & $9(41)$ & $7(35)$ & $16(38)$ & \\
\hline Intergluteal/perianal & $2(9)$ & $0(0)$ & $2(5)$ & \\
\hline Genital & $1(5)$ & $0(0)$ & $1(2)$ & \\
\hline Missing & 51 & 69 & 120 & \\
\hline Nail involvement at first $\mathrm{PsO}$ diagnosis, $\mathrm{n}(\%)$ & $24(42)$ & $23(35)$ & $47(38)$ & 0.41 \\
\hline No documentation, $\mathrm{n}$ & 16 & 23 & 39 & \\
\hline
\end{tabular}




\begin{tabular}{|c|c|c|c|c|}
\hline & $\leq 2$ yrs, $n=73$ & $>2 \mathrm{yrs}, \mathrm{n}=89$ & Total, $\mathrm{n}=162$ & $P$ \\
\hline Family history of PsA, n (\%) & $6(12)$ & $6(11)$ & $12(11)$ & 0.84 \\
\hline Missing, $\mathrm{n}$ & 22 & 32 & 54 & \\
\hline Enthesitis at or prior to PsA diagnosis, n (\%) & $16(22)$ & $35(39)$ & $51(31)$ & 0.02 \\
\hline Dactylitis at or prior to PsA diagnosis, $\mathrm{n}(\%)$ & $35(48)$ & $35(39)$ & $70(43)$ & 0.27 \\
\hline Inflammatory back pain at or prior to PsA diagnosis, $\mathrm{n}(\%)$ & $4(5)$ & $13(15)$ & $17(10)$ & 0.06 \\
\hline $\operatorname{ESR}(\mathrm{mm} / \mathrm{h})$ at PsA diagnosis, mean $(\mathrm{SD})$ & $18.9(18.3)$ & $18.2(15.3)$ & $18.5(16.8)$ & 0.95 \\
\hline Missing, $\mathrm{n}$ & 4 & 17 & 21 & \\
\hline $\mathrm{CRP}(\mathrm{mg} / \mathrm{L})$ at PsA diagnosis, mean (SD) & $16.5(32.4)$ & $13.6(19.0)$ & $14.9(26.0)$ & 0.87 \\
\hline Missing & 22 & 29 & 51 & \\
\hline Radiographic damage, $\mathrm{n}(\%)$ & $16(22)$ & $28(31)$ & $44(27)$ & 0.19 \\
\hline Missing, $\mathrm{n}$ & 1 & 0 & 1 & \\
\hline
\end{tabular}

BSA: body surface area; CRP: C-reactive protein; ESR: erythrocyte sedimentation rate; GPP: generalized pustular psoriasis; PPP: palmoplantar pustulosis psoriasis; PsA: psoriatic arthritis; $\mathrm{PsO}$ : psoriasis.

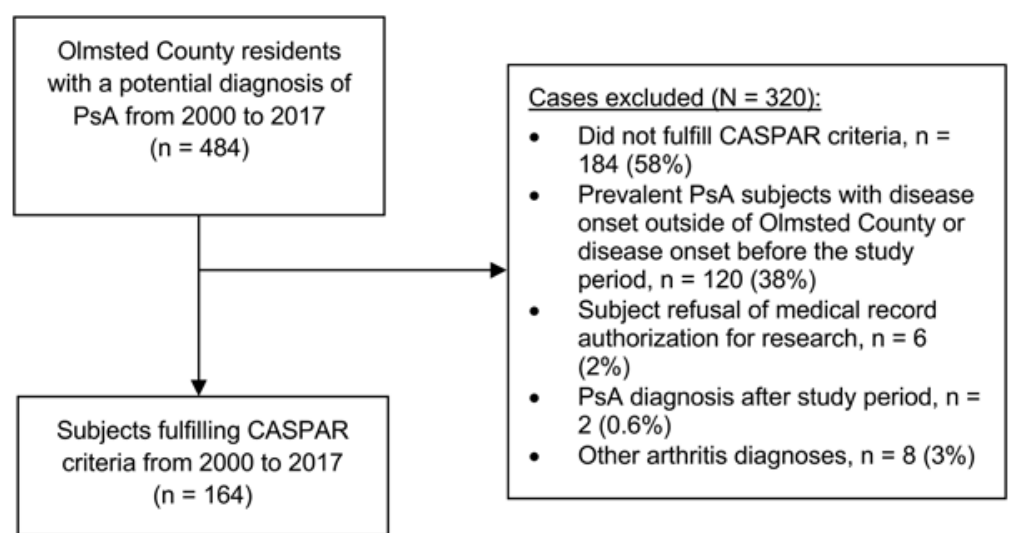

Figure 1. Case-finding strategy for PsA from the medical records. CASPAR: ClASsification of Psoriatic Arthritis; PsA: psoriatic arthritis.

was not statistically significant. Results were similar for diagnostic delays of 6 months or 1 year.

\section{DISCUSSION}

In this population-based study, more than half of the patients with PsA were diagnosed at least 2 years after symptom onset. Younger age at PsA symptom onset, obesity, and enthesitis were associated with a delay in diagnosis of longer than 2 years. The importance of diagnosing PsA early has been outlined in several studies, and a delay in diagnosis has been shown to be associated with poor outcomes in PsA. Studies from the United Kingdom and Canada show that a diagnostic delay greater than 1 year and 2 years, respectively, were associated with worse functional outcomes. ${ }^{2,3}$ Observational studies have reported improved outcomes in patients with PsA receiving early treatment; these improved outcomes may be long-lasting. ${ }^{2,3,4,5}$ While PsA can sometimes be mild, requiring minimal pharmacological therapy, high-risk patients may benefit from earlier diagnosis. Therefore, additional efforts are needed to shorten the time from symptom onset to diagnosis.
Several patient- and system-related factors may contribute to delay of diagnosis: (1) patient behavior, (2) practitioner delay in recognition or referral, and (3) system delays (i.e., time to rheumatology visit). ${ }^{16,17}$ Our study found that patients with younger age at PsA symptom onset, higher BMI, or enthesitis before diagnosis were more likely to have a diagnostic delay of $\geq 2$ years. It is possible that younger patients will dismiss their symptoms. Similarly, patients may not report joint pain symptoms or may not be aware of joint inflammation. ${ }^{6}$ Symptoms such as enthesitis may be attributed to overuse and trauma. Obese patients may attribute joint symptoms to more commonly associated diseases such as $\mathrm{OA}$ or gout. Longer time to diagnosis ( 5.7 vs $2.8 \mathrm{yrs}$ ) was also noted in obese patients compared to patients with normal BMI in the University of Toronto PsA cohort. ${ }^{18}$

Similarly, delay could be related to provider misattribution of PsA signs or symptoms to more common conditions, such as trauma, overuse, degenerative disease, fibromyalgia, or gout. In a US patient survey, less recognized symptoms of PsA, such as enthesitis and back pain, were also associated with diagnostic delay. ${ }^{19}$ Inflammatory back pain symptoms were not 


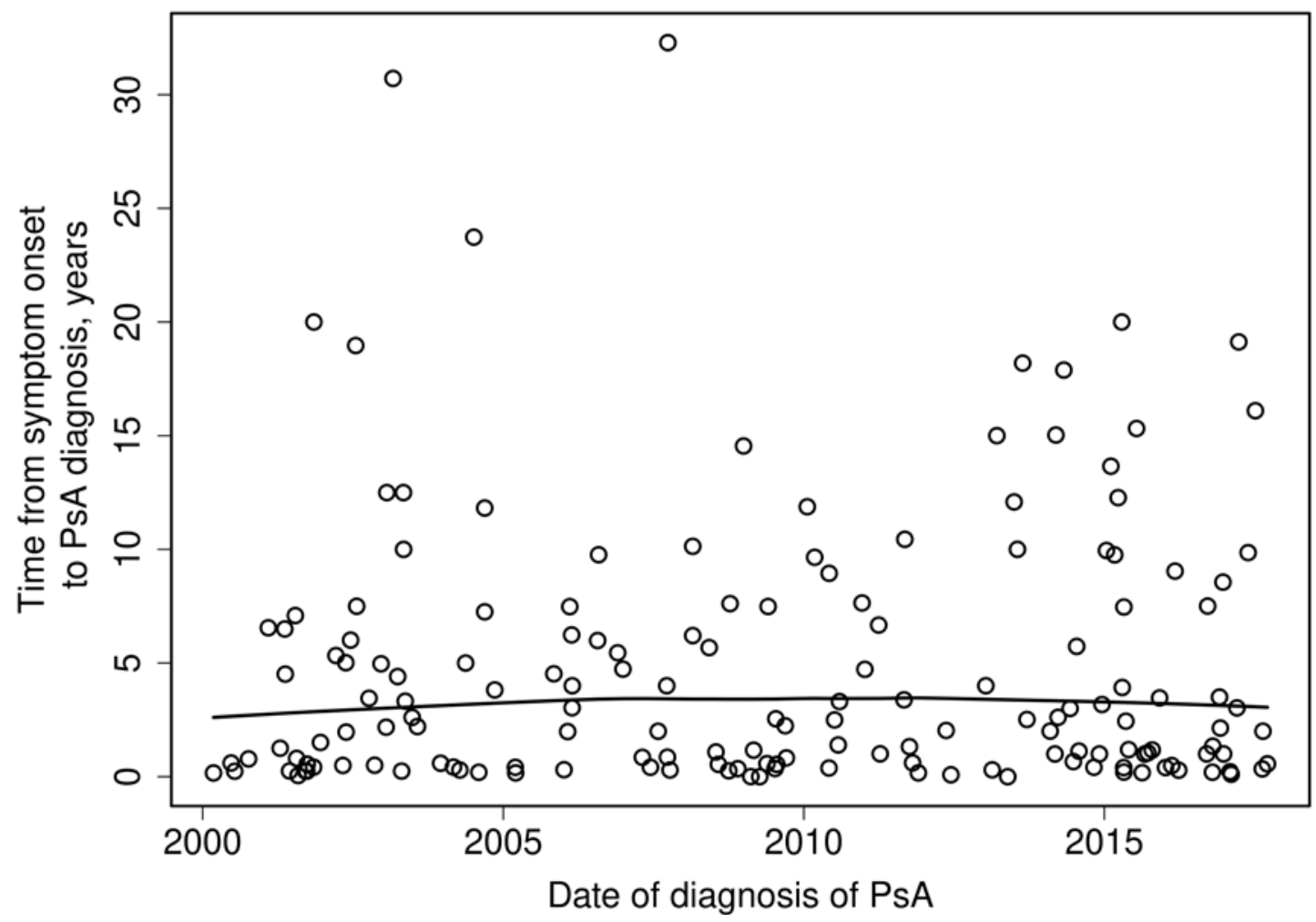

Figure 2. Trend over time (2000-2017) in diagnostic delay from symptom onset to diagnosis of PsA. PsA: psoriatic arthritis.

Table 2. Logistic regression models for delay in PsA diagnosis adjusted for age at symptom onset and sex.

\begin{tabular}{lccc}
\hline & $>2$ Years & $\begin{array}{c}>1 \text { Year } \\
\text { OR }(95 \% \mathrm{CI})\end{array}$ & > 6 Months \\
\hline Age at PsA symptom onset per 10 -yr decrease & & & \\
BMI at PsA diagnosis per $10 \mathrm{~kg} / \mathrm{m}^{2}$ increase & $1.34(1.04-1.74)$ & $1.26(0.97-1.65)$ & $1.35(1.00-1.82)$ \\
Enthesitis prior to PsA & $1.89(1.15-3.10)$ & $1.73(1.03-2.92)$ & $1.58(0.89-2.81)$ \\
ESR at PsA diagnosis per $10 \mathrm{~mm} / \mathrm{h}$ increase & $1.20(1.08-4.46)$ & $1.75(0.83-3.68)$ & $2.27(0.91-5.63)$ \\
Type of psoriasis at first diagnosis (sebopsoriasis) & $0.19(0.04-0.97)$ & $0.21(0.05-0.89)$ & $0.10(0.02-0.45)$ \\
Radiographic damage & $1.63(0.78-3.41)$ & $1.55(0.71-3.38)$ & $1.94(0.77-4.92)$
\end{tabular}

${ }^{a}$ Adjusted for sex only. ESR: erythrocyte sedimentation rate; PsA: psoriatic arthritis.

different between patients with and without diagnostic delay in our study. An important and novel finding of our study is the association of obesity with diagnostic delay. BMI is accurately captured in the REP database, with height and weight captured at each visit. Obesity could make the joint examination difficult; other concurrent joint pathologies, such as degenerative disease and gout, are also more common in obesity. In the absence of apparent $\mathrm{PsO}$ or other extraarticular manifestations of spondyloarthritis, manifestations of enthesitis and joint symptoms in obese patients may not be diagnosed until late after the development of objective clinical or radiologic findings. In our study, patients with sebopsoriasis were less likely to have a diagnostic delay. While it is debatable whether this is a true $\mathrm{PsO}_{s}$ variant, early diagnosis of sebopsoriasis by a dermatologist could aid rheumatologists in diagnosing a patient with PsA in the right setting.
Previous studies have examined time to PsA diagnosis, and the results have been variable. In a study from Denmark, the average time from initial symptoms to diagnosis was 3.42 years (SD 4.75). ${ }^{10}$ Another study from an older referral cohort (University of Toronto) using CASPAR criteria reported that $60 \%$ of patients had $>2$ years of symptoms (median $11 \mathrm{yrs}$ in this group) before PsA diagnosis. ${ }^{2}$ The reported times to diagnosis in other studies are slightly better. A study from the UK using CASPAR criteria showed that only one-third of patients had a symptom duration of $\geq 1$ year before diagnosis. ${ }^{3}$ Similarly, another study from a rheumatology clinic in Dublin reported the median time from symptom onset to first rheumatologic assessment was 1 year (IQR $0.5-2$ ). 5 The outcome in that study was the first rheumatologic assessment rather than an established diagnosis of PsA, which could explain the lower median delay in the study compared to ours. Finally, in a cross-sectional 
Web-based survey from the US, one-third of PsA patients sought medical attention after 1 year of symptom onset; up to one-third of the patients had $\geq 5$ years between seeking medical attention and receiving a diagnosis. ${ }^{19}$ However, the results of this survey study should be interpreted in the context of the limitations of surveys, including potential recall, participation, or ascertainment bias with regard to PsA diagnosis (e.g., self-reported diagnosis).

Secular trends in diagnostic delay have not been robustly studied. The study from Denmark showed improvement in time to diagnosis of PsA from 2000 to 2011 (42 months in 2000-2002 to 7 months in 2009-2011). ${ }^{10}$ This study was conducted within the DANBIO registry, where patient eligibility was restricted to patients on biologic therapy (i.e., only patients with severe PsA) and included before 2005. Similarly, recall bias was a potential concern in this study, especially in patients with longer symptom duration because symptom onset was collected at study registration. In our study, we did not find a change in time to diagnosis between 2000 and 2017.

Improvement in identification and subsequent referral of patients with inflammatory arthritis will require a concerted effort. The Psoriatic Arthritis Forum consensus had recommended identification of cases in the community, public awareness programs, patient education, self-administered surveys, referral guidelines for community practitioners, and integrated multidisciplinary clinics with dermatologists and rheumatologists. ${ }^{7}$ Use of some of these approaches has been shown to improve diagnostic delays. ${ }^{20}$ Additionally, some validated screening tools in $\mathrm{PsO}$ could help capture PsA features such as enthesitis and back pain. ${ }^{21}$ Advanced imaging techniques, such as ultrasound in clinical practice, could improve detection of enthesitis and joint inflammation in obese patients. Moreover, our results emphasize the complicated relationship between comorbidities such as obesity and PsA. Delay in diagnosis could be another possible mechanism associated with worse outcomes in obesity, in addition to lower response to therapy.

Strengths of our study include the unique record linkage system of the REP, allowing near-complete ascertainment of all clinically recognizable PsA cases in a well-defined population. ${ }^{12}$ Further, case ascertainment was done using the validated CASPAR criteria. Unlike administrative coding in most studies, all variables were collected through manual review of the paper and electronic records.

However, our study also has several limitations. While few PsA cases not fulfilling CASPAR criteria may have been missed, the sensitivity and specificity of the CASPAR criteria were close to $99 \%$ when adapted for retrospective use to identify PsA cohort. ${ }^{22}$ Due to the extended study period and availability of near-complete medical history in this population, we expect that most PsA cases would have been correctly ascertained. Second, being a retrospective study, the usual limitations regarding completeness of medical record documentation apply. Only those symptoms recorded in the medical records would be ascertained, and the precision/accuracy of exact symptom onset is uncertain. While our study did not examine patient-reported or functional outcomes, a possible association of diagnostic delay with radiographic damage was seen. However, this association did not reach statistical significance, perhaps due to the limited sample size of the cohort, and temporality could not be ascertained due to lack of radiographs before PsA diagnosis in most cases. Although the radiology reports were thoroughly reviewed, formal scoring by a radiologist was not performed. Last, the population of Olmsted County, Minnesota, is predominantly White (90\%), which may limit the generalizability of study results to other racial or ethnic groups.

In conclusion, more than half of the PsA patients in our study had a diagnostic delay of $>2$ years, and no significant improvement in time to diagnosis was noted from 2000 to 2017. Patients with younger age at PsA symptom onset, higher BMI, or enthesitis before diagnosis were more likely to have a diagnostic delay of $>2$ years. A better understanding of factors associated with diagnostic delay may help in earlier diagnosis and management to improve outcomes in high-risk PsA patients. As not all patients have severe or progressive disease, identifying high-risk patient subgroups will be important to stratify those who will benefit from early, aggressive treatment.

\section{REFERENCES}

1. Sokoll KB, Helliwell PS. Comparison of disability and quality of life in rheumatoid and psoriatic arthritis. J Rheumatol 2001;28:1842-6.

2. Gladman DD, Thavaneswaran A, Chandran V, Cook RJ. Do patients with psoriatic arthritis who present early fare better than those presenting later in the disease? Ann Rheum Dis 2011;70:2152-4.

3. Tillett W, Jadon D, Shaddick G, Cavill C, Korendowych E, de Vries CS, et al. Smoking and delay to diagnosis are associated with poorer functional outcome in psoriatic arthritis. Ann Rheum Dis 2013;72:1358-61.

4. Theander E, Husmark T, Alenius GM, Larsson PT, Teleman A, Geijer M, et al. Early psoriatic arthritis: short symptom duration, male gender and preserved physical functioning at presentation predict favourable outcome at 5-year follow-up. Results from the Swedish Early Psoriatic Arthritis Register (SwePsA). Ann Rheum Dis 2014;73:407-13.

5. Haroon M, Gallagher P, FitzGerald O. Diagnostic delay of more than 6 months contributes to poor radiographic and functional outcome in psoriatic arthritis. Ann Rheum Dis 2015;74:1045-50.

6. Ogdie A, Weiss P. The epidemiology of psoriatic arthritis. Rheum Dis Clin North Am 2015;41:545-68.

7. Helliwell P, Coates L, Chandran V, Gladman D, de Wit M, FitzGerald O, et al. Qualifying unmet needs and improving standards of care in psoriatic arthritis. Arthritis Care Res 2014;66:1759-66.

8. Ritchlin CT, Colbert RA, Gladman DD. Psoriatic Arthritis. N Engl J Med 2017;376:957-70.

9. Coates LC, Helliwell PS. Psoriatic arthritis: state of the art review. Clin Med 2017;17:65-70.

10. Sørensen J, Hetland ML, all departments of rheumatology in Denmark. Diagnostic delay in patients with rheumatoid arthritis, psoriatic arthritis and ankylosing spondylitis: results from the Danish nationwide DANBIO registry. Ann Rheum Dis 2015;74:e12.

11. Rocca WA, Yawn BP, St Sauver JL, Grossardt BR, Melton LJ 3rd. History of the Rochester Epidemiology Project: half a century of medical records linkage in a US population. Mayo Clin Proc 2012;87:1202-13. 
12. St Sauver JL, Grossardt BR, Yawn BP, Melton LJ 3rd, Pankratz JJ, Brue SM, et al. Data resource profile: the Rochester Epidemiology Project (REP) medical records-linkage system. Int J Epidemiol 2012;41:1614-24.

13. Taylor W, Gladman D, Helliwell P, Marchesoni A, Mease P, Mielants $\mathrm{H}$, et al. Classification criteria for psoriatic arthritis: development of new criteria from a large international study. Arthritis Rheum 2006;54:2665-73.

14. A Delphi consensus study to standardize terminology for the pre-clinical phase of psoriatic arthritis [Internet]. ACR Meeting Abstracts. [Internet. Accessed April 19, 2021.] Available from acrabstracts.org/abstract/a-delphi-consensus-study-to-standardizeterminology-for-the-pre-clinical-phase-of-psoriatic-arthritis

15. van der Heijde D, Gladman DD, Kavanaugh A, Mease PJ. Assessing structural damage progression in psoriatic arthritis and its role as an outcome in research. Arthritis Res Ther 2020;22:18.

16. Hansen RP, Olesen F, Sørensen HT, Sokolowski I, Søndergaard J. Socioeconomic patient characteristics predict delay in cancer diagnosis: a Danish cohort study. BMC Health Serv Res 2008;8:49.

17. Hansen RP, Vedsted P, Sokolowski I, Søndergaard J, Olesen F. General practitioner characteristics and delay in cancer diagnosis. A population-based cohort study. BMC Fam Pract 2011;12:100.
18. Eder L, Abji F, Rosen CF, Chandran V, Gladman DD. The association between obesity and clinical features of psoriatic arthritis: a case-control study. J Rheumatol 2017;44:437-43.

19. Ogdie A, Nowell WB, Applegate E, Gavigan K, Venkatachalam S, de la Cruz M, et al. Patient perspectives on the pathway to psoriatic arthritis diagnosis: results from a web-based survey of patients in the United States. BMC Rheumatol 2020;4:2.

20. van Onna M, Gorter S, Maiburg B, Waagenaar G, van Tubergen A. Education improves referral of patients suspected of having spondyloarthritis by general practitioners: a study with unannounced standardised patients in daily practice. RMD Open 2015;1:e000152.

21. Iragorri N, Hazlewood G, Manns B, Danthurebandara V, Spackman E. Psoriatic arthritis screening: a systematic review and meta-analysis. Rheumatology 2019;58:692-707.

22. Tillett W, Costa L, Jadon D, Wallis D, Cavill C, McHugh J, et al. The ClASsification for Psoriatic ARthritis (CASPAR) criteria - a retrospective feasibility, sensitivity, and specificity study. J Rheumatol 2012;39:154-6. 